\title{
Visual symptoms in the migraine syndrome
}

\author{
V. C. Hachinski, M.D., J. Porchawka and J. C. Steele, M.D.
}

- This report concerns the visual phenomena 100 children experienced during attacks of migraine, emphasizes how common these phenomena are, and considers the physiologic and anatomic mechanisms producing visual impairment, scotomas, distortions and hallucinations.

Migrainous visual symptoms, familiar to many physicians from personal experience, often herald or accompany head pain and often indicate the severity of the attack that is to follow. Migraine and its visual accompaniments are as common in childhood as in adulthood. Visual symptoms tend to be unique, distinct and sterotyped for the individual. A clear description of them is of value, for when associated with other systemic and neurologic accompaniments they permit a firmer diagnosis of migraine, reducing the need for detailed neuroradiographic study.

\section{Historical background}

Three thousand years ago, an Assyrian medical writer described dazzling of the eyes, obscuration of vision, and starlike spots shining before both eyes during daylight. His graphic account was likely the first record of the visual phenomena that occur with migraine. In the following millenium, Hippocrates recognized the clinical entity featured by intermittent visual 570 disturbance, headache and vomiting. ${ }^{1}$ Several hundred years later, Aretaeus of Cappadoccia reemphasized the visual disturbances of migraine. ${ }^{2}$ Descriptions of transient visual aberrations can be found in the writings of the Middle Ages. One of the most striking accounts is that by the Abbess Hildegard of Bingen. Her twelfth-century theologic manuscripts vividly illustrate her mystical experiences. The drawings, elaborated by contemporary and traditional artistic symbolism, indicate that many of her visions were migrainous distortions. ${ }^{3}$ In the eighteenth century, a physician who had migraine described his personal visual experiences. ${ }^{4}$ Liveing ${ }^{5}$ published a detailed treatise on migraine and included an account of varied visual symptoms. The astronomer Airy ${ }^{6}$ and his physician son illustrated the patterns and evolutions of their own migrainous auras. Gowers, Jolly, ${ }^{8}$ Lashley ${ }^{9}$ and Richards ${ }^{10}$ have since recorded sequences of the visual changes that

From the Division of Neurology and the Department of Visual Education, The Hospital for Sick Children, Toronto, Ontario.

This paper was read in part at the twenty-third annual meeting of the American Academy of Neurology, New York, April 30, 1971 .

Received for publication October 9, 1973.

Dr. Hachinski's address is c/o Dr. J. S. Prichard, Division of Neurology, The Hospital for Sick Children, 555 University Avenue, Toronto 101, Ont. 


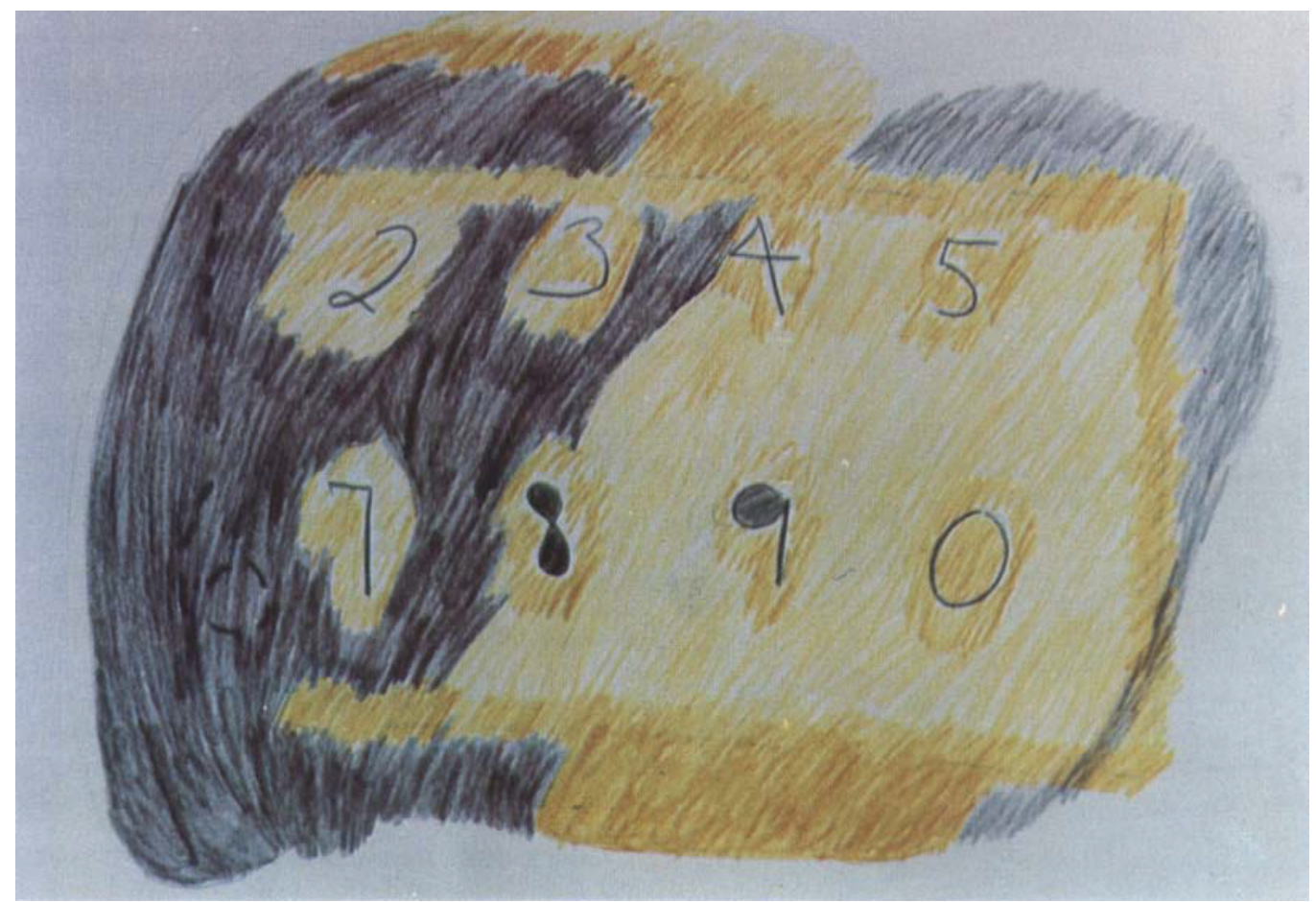

Figure 1. Hemianopia in case 3. This number chart was obscured on the left and unusually bright on the right side.

accompany attacks of migraine that occur in adulthood.

While it is recognized that visual symptoms are equally a feature of migraine in children, ${ }^{1-13}$ little attempt has been made to describe and document these varied experiences. To provide a detailed account of such phenomena, we interviewed a number of children, requesting that they describe what they experienced and draw what they saw during their attacks of migraine.

\section{Materials and methods}

Among 244 children with migraine examined at The Hospital for Sick Children, Toronto, Ontario, between 1959 and 1971, 100 experienced visual phenomena associated with the headache, an incidence of 41 percent. The diagnosis of migraine had been made when paroxysmal headaches occurred in otherwise healthy children and attacks were accompanied by systemic or neurologic symptoms, or both. In most cases, other family members had migraine or periodic head pain. Of the patients seen before
1969, 27 percent complained of blurred vision, of seeing spots, or of things looking "funny" when they had a headache. By contrast, after 1969, 63 percent volunteered the information or responded positively to variations of the question, "What else happens when you have a headache?"

We noted the age, sex, age of onset of headache, age of onset of visual phenomena, family history of migraine, and presence or absence of neurologic findings to establish the diagnosis.

Sixty-seven of the 100 children were recalled and interviewed independently by a clinician and a medical artist regarding visual experiences. The artist encouraged the children to draw what they had seen during an attack, and these pictures are reproduced without changes.

\section{Results}

Of the 100 patients, 53 were girls and 47 boys. Their symptoms had begun between two and 17 years of age, and in 96, headache followed or accompanied the visual phenomena. The mean age of onset of headache was eight years, 


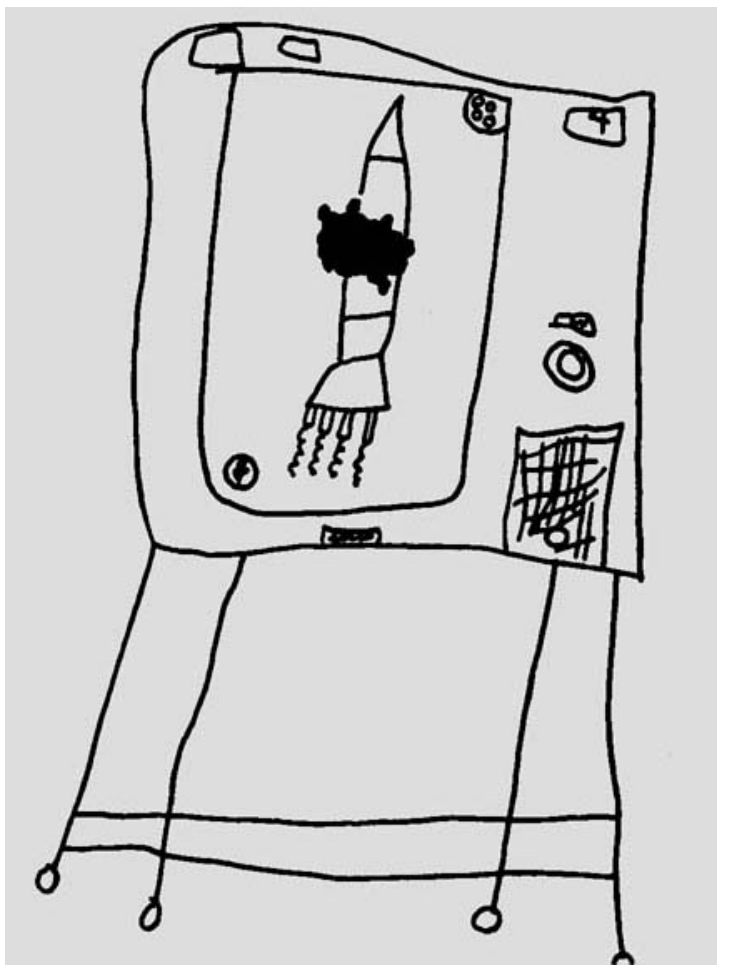

Figure 2. Central scotomas in case 4. Central, bright, flickering red spot composed of smaller spots.

and the mean age of onset of visual phenomena was nine years. Sixty-three patients had other close family relatives who had migraine. The results of neurologic examinations between attacks were normal in all children except three who had residual and persistent visual field defects. Visual symptoms usually preceded the onset of headache but occasionally were present during or after it. In several patients, the visual symptoms occurred independently of head pain.

The most common visual symptoms in order of frequency were visual impairment, scotomas, distortion and hallucinations. Representative cases are cited, some illustrated by the child's drawing.

\section{Case reports}

Visual impairment and binocular scotomas. Seventy-seven of the 100 patients had visual impairment or binocular scotomas.

Case 1. For two years this four year old adopted girl had had frequent episodes during which she screamed, cried, and held her head. These attacks occurred spontaneously and lasted 15 to 30 minutes.
During many of them, she became blind, complained of everything being black, bumped into walls, and tripped over furniture.

Case 2. This 16 year old boy had had recurrent headaches for four years. Several months before he was first examined, he partly printed, partly wrote the following account of one of his headaches while he was experiencing it. Spelling has not been corrected.

"December 13th, 1970 at 10.15 a.m. This is my worst headache in two months. I am writing this to keep my mind on something else beside pain. I woke up at 7.00, my left eye was seeing a blurry, distorted pitcher of the room ... by $8.00 \mathrm{my}$ left eye had developd a stabing pain. Between 8.00-8.30 the blood vein in the back of my left eye felt they were dubling in size, also the blood vessels on both sides of my forehead had swelled. By 9.00 a throbing had developed in the left eye, my forehead, and my temples and both of the sides of my head. At aproxmatly 9.30 my head seemed to weight a ton.... By aprox 20 to 10 I had lost all controll over my equaliebereium .... My face was numb now and my stomach felt flutery .... I felt like I was going to vomit. Finally at 12.00 o'clock the pain began to go away."

On rereading his account when he had recovered, he realized that he had misspelled many words, his composition was confused, and he had mixed printing and writing.

Case 3. Since the age of eight years this schoolgirl had had attacks of vertigo often associated with an inability to see well to one or the other side. Figure 1 is her drawing of a chart. The part she was able to make out appeared unusually bright but, to the left, the chart was obscured and those numbers she did perceive were surrounded by dark margins. The visual

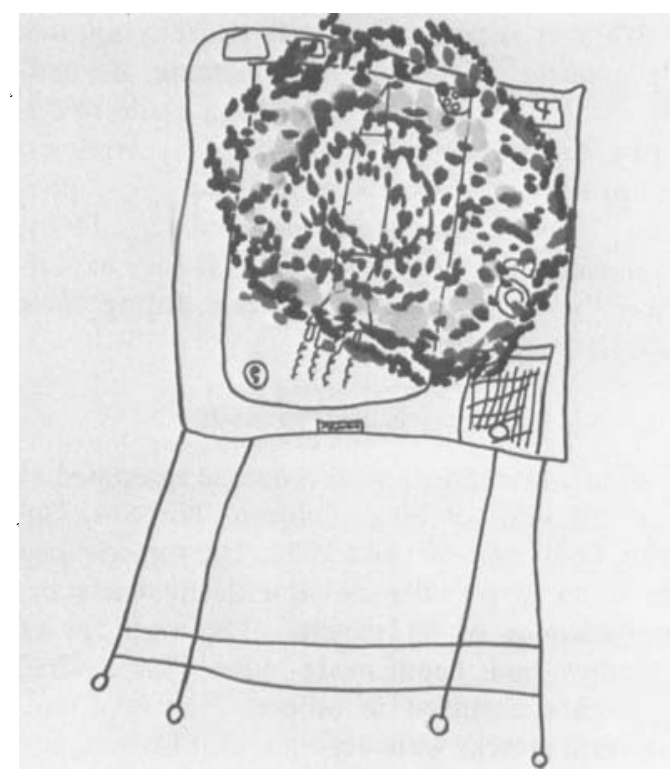

Figure 3. Case 4. The central spot quickly expands into concentric circles of multicolored dots. 


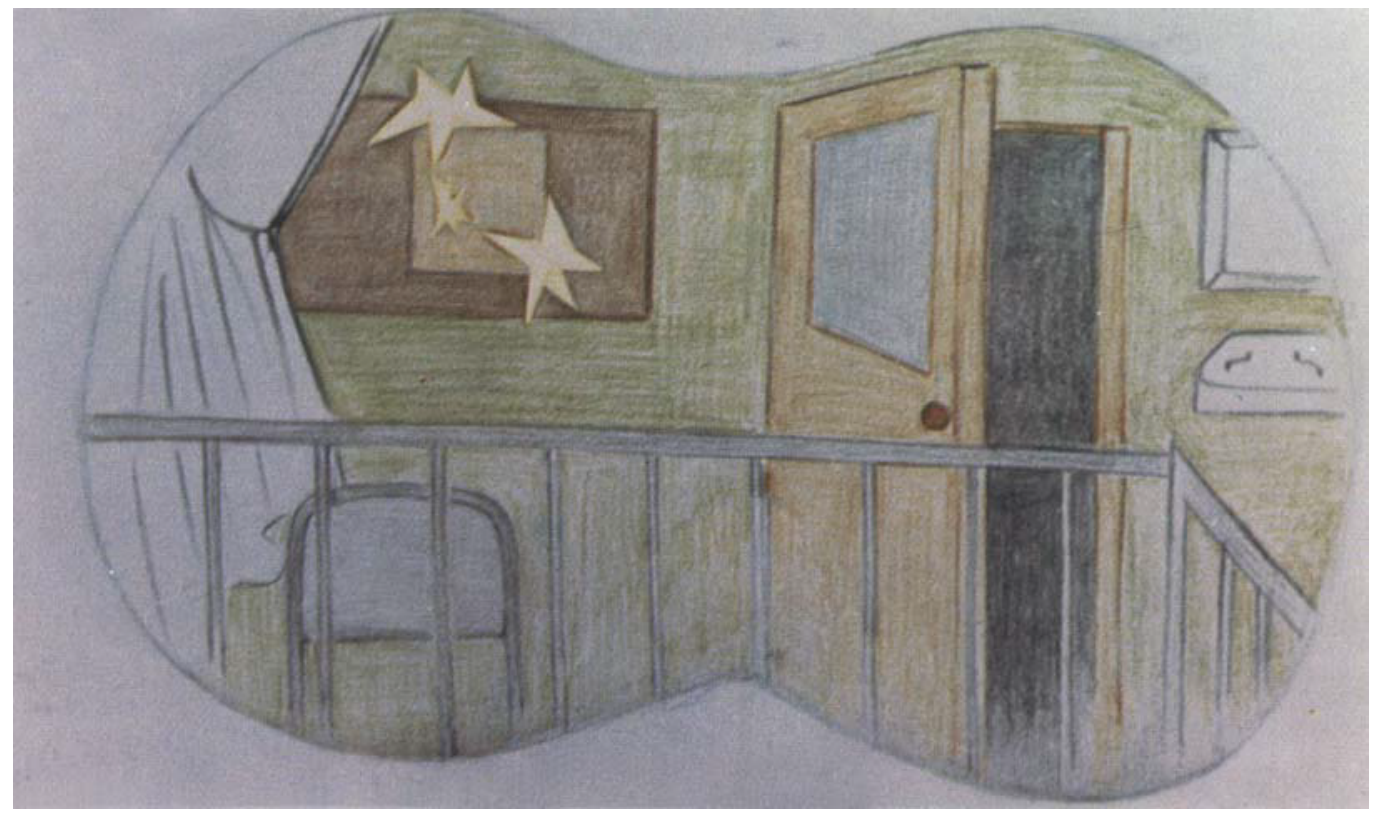

Figure 4. Peripheral scotomas in case 5. Small atypical stars moving slowly from left to right.

change remained for 15 minutes and then it gradually resolved as unilateral throbbing temporal pain developed.

Comment. Total obscuration of vision was more common than hemianopia. Altitudinal or quadratic defects were unusual but did occur. These visual defects were perceived by both eyes.

The patients' descriptions of visual loss varied considerably, and no two children described the same change. However, it was usual for the same symptom to recur in the same patient, although not all headaches were preceded or accompanied by visual phenomena.

In many patients the defect began peripherally and advanced slowly over several minutes, although in some it began abruptly. The obscuration appeared immediately before the eyes in a few and at a fixed distance in others. In some patients, it was the surface or object regarded that was totally or partially obscured. Several older children were unaware of a field defect but did admit to missing things to one or the other side when they looked straight ahead.

Case 4. This nine year old boy has had intermittent and alternating hemicrania for several years. The headache is usually preceded by a few seconds of vertigo. He then sees a bright red, central flickering spot composed of many smaller spots (figure 2 ). The central

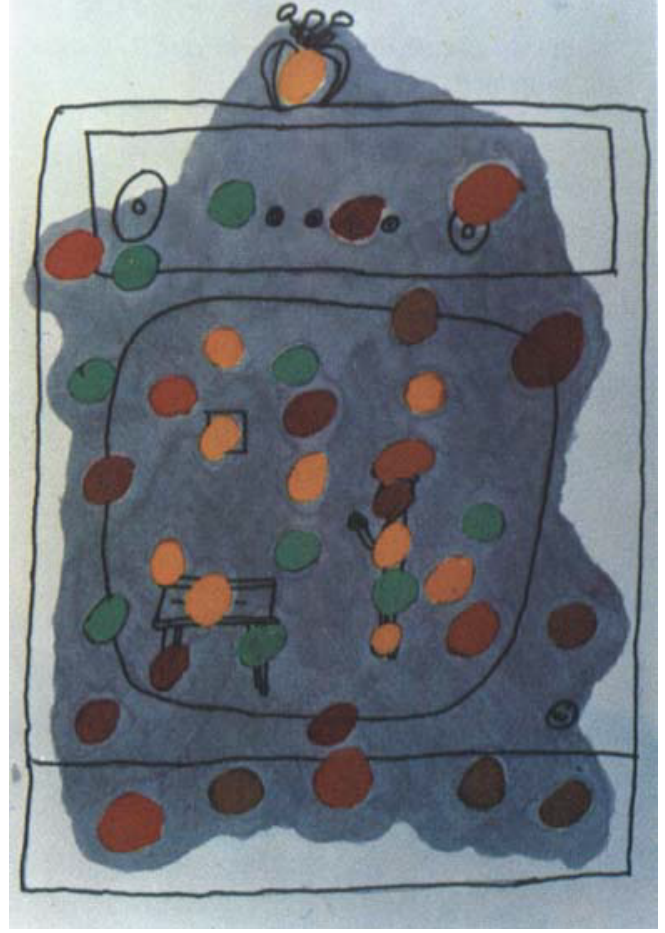

Figure 5. Central and peripheral scotomas in case 6. Initially obscuration of vision is present. On this dark background, multicolored stationary circles appear centrally and peripherally. 


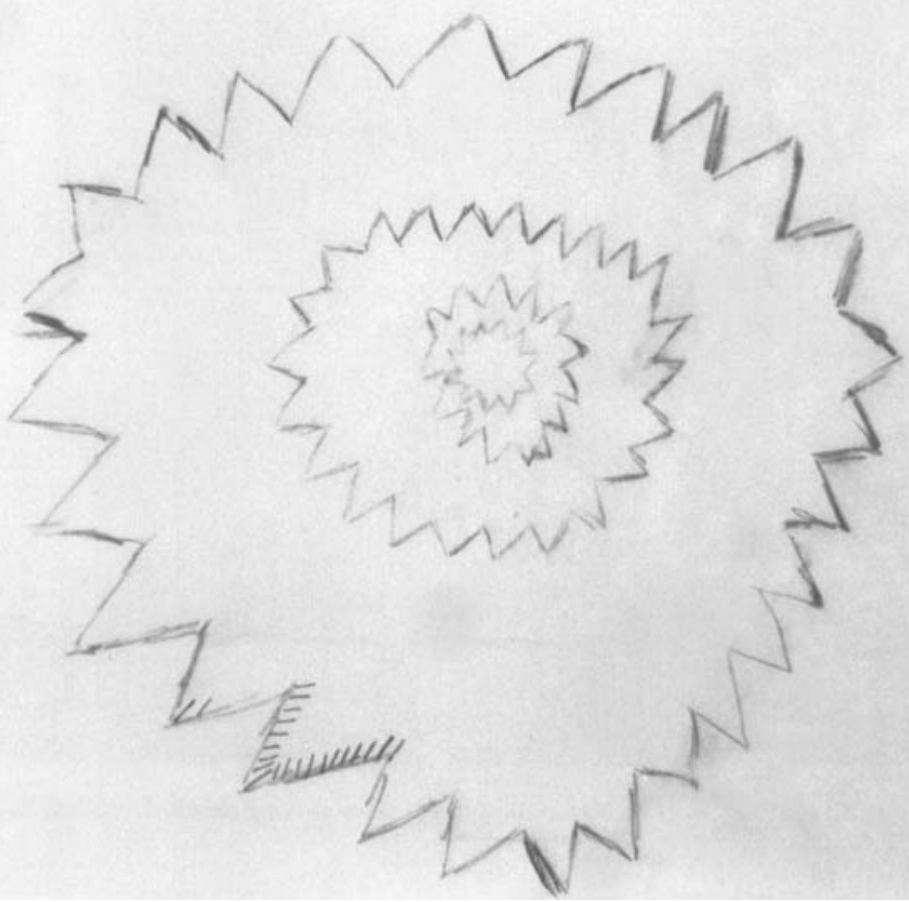

Figure 6. Fortification figure in case 7. Central, concentric, serrated circles with subsidiary bright spokes (bottom left).

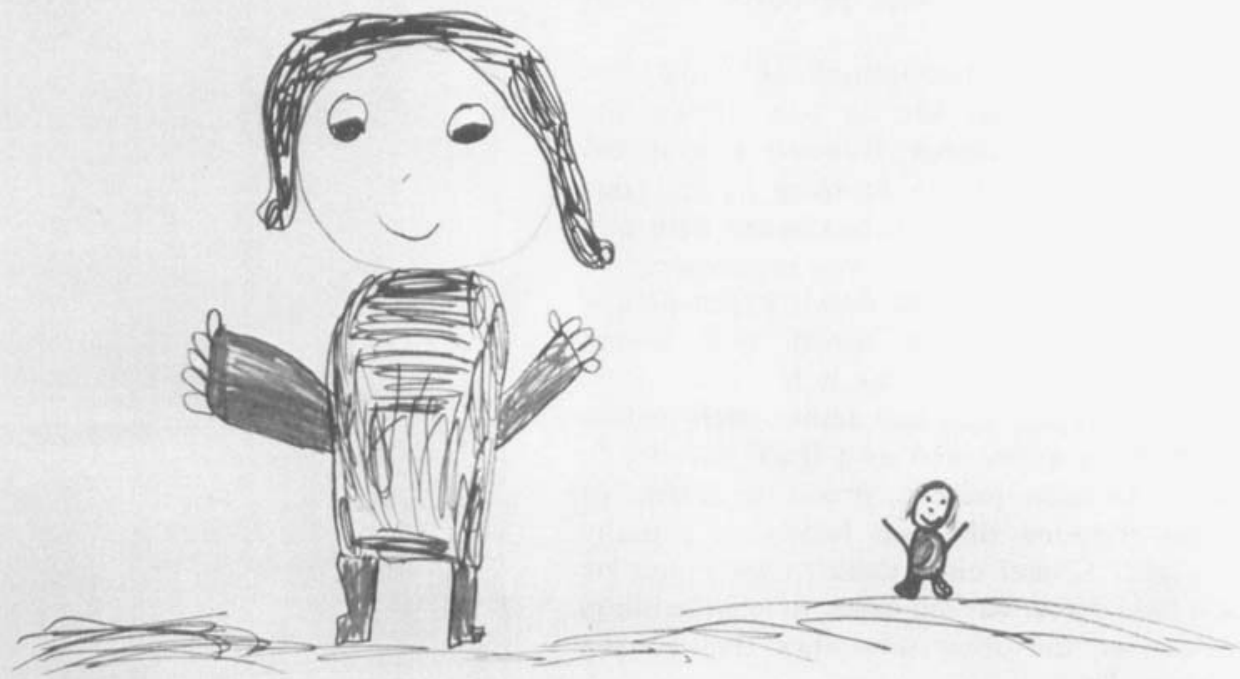

Figure 7. Metamorphopsia in case 8. Other children (right) appeared unusually small to the patient (left). 


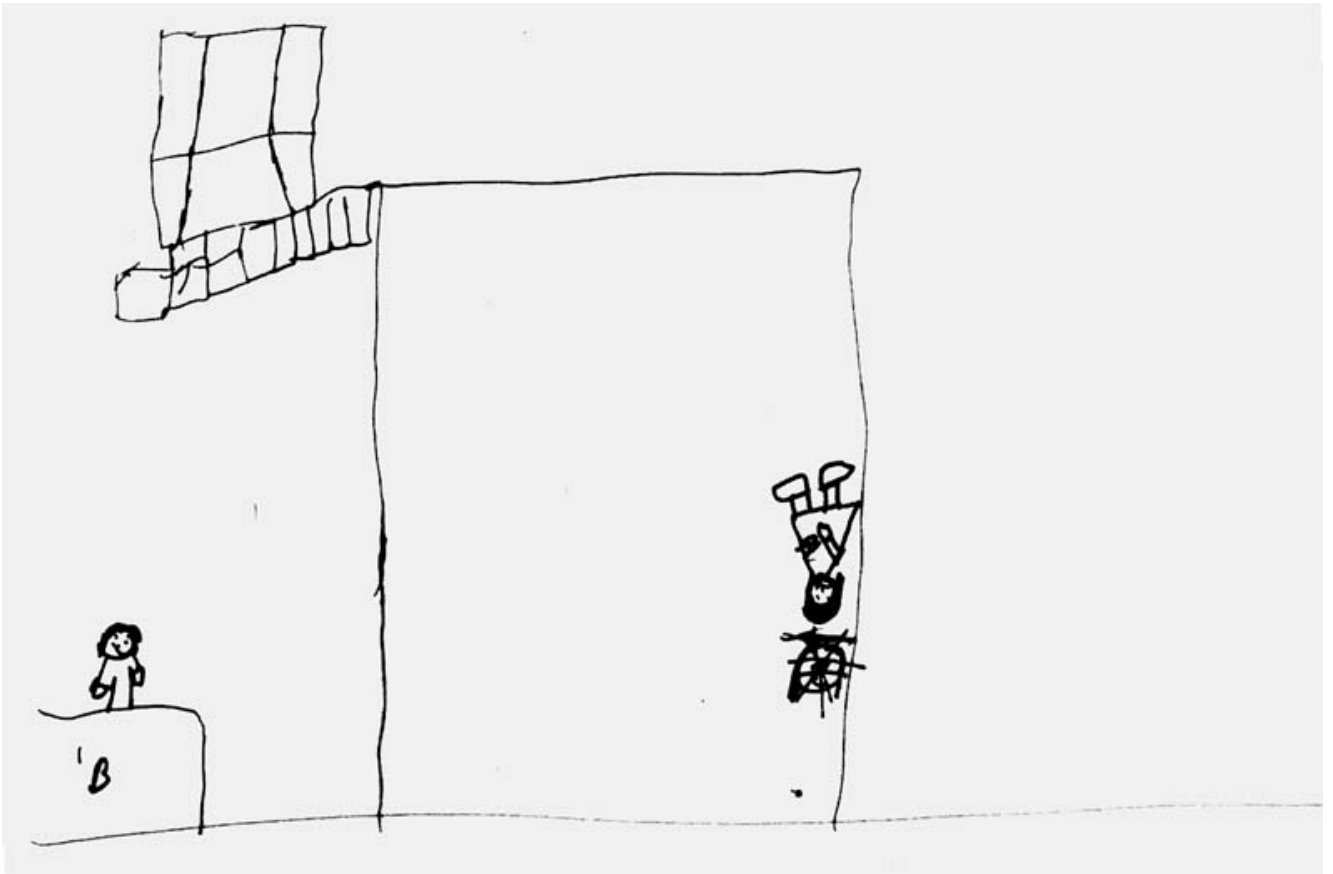

Figure 8. Inversion in case 9. A picture in the room (left upper corner) and the patient's mother (right) appeared upside down.

scotoma quickly expands into concentric circles of multicolored spots that obscure whatever he looks at (figure 3). As the scotomas slowly fade and the colors become less intense, a steady pain develops above one or the other eye and spreads to the temple.

Case 5. This 14 year old girl had had unilateral frontal headaches for two years. Often before the pain began, she would see small, white, distorted stars moving slowly from left to right whether her eyes were open or closed (figure 4). Occasionally, the scotomas occurred during the headache.

Case 6. For the past five years this 11 year old boy has had difficulty seeing to the right and needs to use his finger to follow print when reading. He has had intermittent headache for at least six years. Often during the headache his vision blurs and he sees multicolored circles, which are stationary and appear to be immediately in front of his eyes (figure 5). The symptom may last for 2 to 10 minutes and recur before his headache subsides. On occasion, he experiences vertigo and diplopia before the onset of headache, but these are not necessarily accompanied by visual symptoms. Results of a physical examination were normal except for a right homonymous hemianopia with preservation of central vision. Results of cerebral angiography and electroencephalography were normal.

Case 7. One year before consultation, this 17 year old girl had received a blow to the left eye. Onehalf hour later, she noticed a round serrated scotoma in the center of vision of both eyes whether they were open or closed (figure 6). It remained 30 minutes and was followed by a severe left hemicrania. She has continued to have attacks of alternating hemicrania. The visual disturbance recurs often; at times, she is also unable to see things off to the left.

Comment. As with visual loss, no two patients described the same symptom. The remarkable feature was the variability of experience, although scotomas tended to be stereotyped for the same individual. The form might be stars, circles, squares or squiggles. Usually these moved within the field of vision and evolved, but on occasion, they were unchanging and stationary. Various patients described them as throbbing, spinning, flickering and swimming. The margins were often said to be well defined but occasionally they shimmered or sparkled.

Visual distortions and hallucinations. Sixteen of the 100 children had visual distortions or hallucinations, or both.

Case 8 . For three months this six year old girl had had episodes during which she suddenly became dizzy and unsteady on her feet. Almost immediately, people about her seemed smaller than normal, although their proportion was not distorted (figure 7). One time, while playing in the snow, she felt that she was unusually large and that an ordinary snowball had become huge and turned blue. The vertigo and visual 
distortion usually lasted only a few minutes, whereas the generalized headache that followed lasted two to three hours. Since early childhood she has had intermittent nocturnal pain in her calves, which she described as "a hammer thumping a nail."

Case 9. For two months this nine year old girl had had episodes that began abruptly with double vision. Then the colors of the objects she looked at changed. She was unable to specify just how but was certain they did. This display was brief and followed by bitemporal headache. On one occasion before the headache began, she saw a picture as being upside down and her mother as walking upside down (figure 8).

Case 10. For the past six years this 18 year old girl has had intermittent occipital headache. For one year her headaches were accompanied at the onset by a darkening of vision generally and by her seeing lightly colored, moving scotomas. Several times she has been aware of visual distortions and described one episode when desks in a school classroom appeared to undulate and the numbers on a wall clock were irregularly spaced. On another occasion, she described an elaborate visual hallucination that occurred as her sight cleared. She saw herself lying on a railroad track with a train passing over her (figure 9). To her left side, against the bedroom wall, were irregular, multicolored scotomas. This hallucination lasted 10 minutes and the accompanying headache lasted three hours.

Uniocular visual symptoms. Seven of the 100 children had visual symptoms confined to one eye. Except for the unilaterality, the ob-

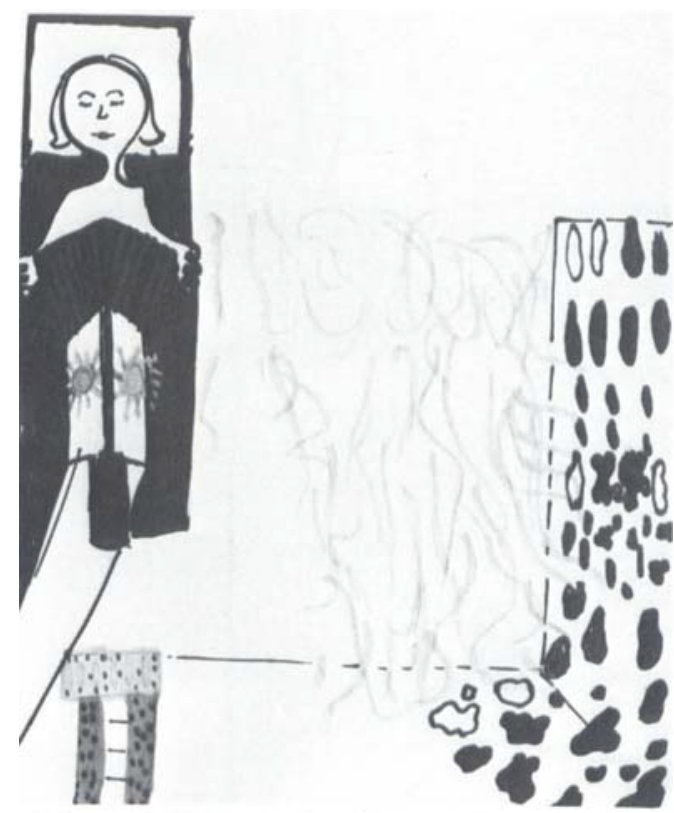

Figure 9. Hallucination in case 10. The patient's room is being viewed from above. She is lying on a railroad track while a train passes over her. To her left against the bedroom wall, there are irregular multicolored scotomas (right lower corner).

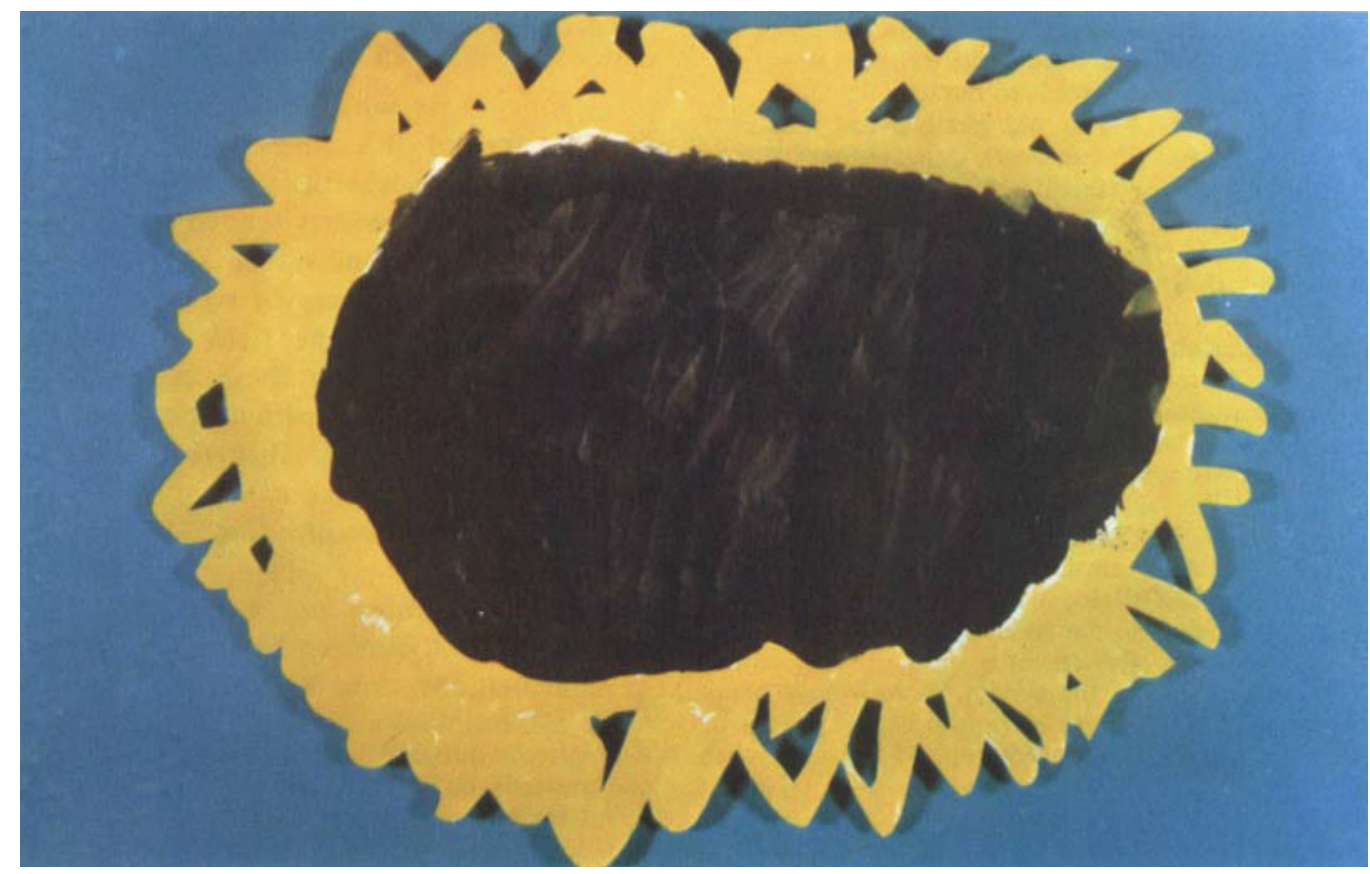

Figure 10. Uniocular scotoma in case 11. Oval, central, dark scotoma surrounded by a bright yellow, shimmering margin. 
scurations and scotomas were similar to those of patients with binocular symptoms. In the majority, intense orbital pain on the affected side occurred.

Case 11. This 17 year old boy became aware of an oval central scotoma surrounded by a bright yellow halo with a shimmering margin in front of his left eye (figure 10). This change lasted 15 minutes and was followed by left frontal headache. Since that time, he has had weekly headaches that are preceded by the same visual symptom. Aura and headache are always on the same side, sometimes right and sometimes left.

\section{Discussion}

In our series of 244 children with migraine, 41 percent experienced visual symptoms as a prodrome or accompaniment of headache. This incidence is comparable to that reported by others. ${ }^{1-13}$ The true incidence of visual change in migraine may be somewhat higher than this, as children are often reluctant to volunteer symptoms they consider bizarre; other children, particularly the young, may not associate what they see with the headache. Physicians often fail to inquire about visual symptoms, and even if the patient reports them, the physician may dismiss the information as unimportant. The headache, malaise, and altered perception may lead the patient to minimize his visual experiences.

Some visual phenomena such as the moving shapes experienced on closing the eyes for sleep, ${ }^{14}$ the light sensation on opening the eyes, ${ }^{15}$ and the fine moving particles sometimes seen against a uniform background ${ }^{16}$ are normal. Our patients were unlikely to be describing physiologic phenomena because what they described at their first examination was similar to that described at review and almost identical with the pictures they drew.

The suggestion that the visual phenomena of migraine are due to impaired circulation dates from the nineteenth century when, in Harris' 17 study, Galeazowski, Du Bois-Reymond and Latham ascribed them to vasomotor spasm. Wolf $\mathrm{f}^{18}$ and co-workers showed that the inhalation of amyl nitrite would arrest the visual aura; this further suggested that symptoms were due to cerebral vasoconstriction.

To interpret the visual symptoms we found it helpful to use an anatomic classification attributing visual phenomena to ischemia in the areas supplied by the posterior cerebral, middle cerebral, and ophthalmic arteries. In 77 pa- tients, binocular visual symptoms or bilateral scotomas, or both, seemed to indicate ischemia within the posterior cerebral artery distribution. Many patients had associated brainstem symptoms of ataxia, vertigo, diplopia, impairment of consciousness, and bilateral limb weakness and paresthesias. Such symptoms suggest the syndrome of basilar artery migraine, an entity first clearly described by Bickerstaff ${ }^{19}$ in 1961. The visual distortions and hallucinations experienced by 16 patients are attributable to ischemia of the temporoparietal regions in the distribution of the middle cerebral artery. In seven patients the visual change was uniocular, indicating that ischemia was in the ophthalmic artery distribution.

$\mathrm{O}^{\prime} \mathrm{Brien}^{20}$ has shown that total cerebral flow decreases during the migrainous aura. The frequency of visual phenomena may be a function of the large number of fibers and nerve cells subserving the visual system. ${ }^{21}$ That visual phenomena are so often attributable to regional ischemia indicates that there must be local dysfunction of vasomotor control with ischemia in addition to biochemical and generalized cerebral dysfunction. ${ }^{22}$ Bruyn and Weenink ${ }^{23}$ have suggested that all neurologic symptoms of migraine can be explained by an ischemic dysfunction of a relatively small, central, subcortical area where the visual and other sensory projections are close together. Why different areas of the brain should be affected at different times is harder to explain. Perhaps the compensatory mechanisms called into action to suppress a migrainous attack will act maximally in the area most affected, rendering it relatively refractory for a given period of time. A new migrainous attack would occur in an alternate region where the threshold was lower.

The visual symptoms of migraine have been variously attributed to paroxysmal electrophysiologic alterations, nerve storms, ${ }^{5}$ a primary derangement of neuroactivity akin to epilepsy, ${ }^{7}$ a form of sensory epilepsy, ${ }^{1}$ a postparoxysmal phenomenon, ${ }^{17}$ and a spreading wave of cortical depression. ${ }^{9}, 24,25$ Recently, Richards ${ }^{10}$ observations have supported this view. This may mean that migraine is biochemically determined and that, while change in vasomotor tone is the predominant manifestation, the cerebral symptoms will also depend on the primary biochemical alteration.

Visual phenomena like those associated with 
migraine can be elicited by other means. By applying electrical stimuli to the visual system through the skull, Knoll and associates ${ }^{26}$ mapped a series of 15 visual patterns that were stereotyped for the individual and reproducible even after intervals of six months. By direct cortical stimulation, Penfield and Jasper ${ }^{27}$ and Penfield and Perot $^{28}$ were able to establish that electrical stimulation of the occipital area produced simple colors, flashes and stars. Stimulation of the temporal lobe produced formed and elaborate hallucinations. Vertebral angiography may produce scintillating scotomas, stars and hallucinations that resemble those observed in migraine. ${ }^{29}$

As we have indicated, the pathophysiologic process determining these changes remains uncertain, but they are likely the consequence of ischemia triggered biochemically.

The paroxysmal occurrence of visual phenomena associated with headache and other systemic vasomotor signs is suggestive of migraine, particularly in the presence of a positive heredity and a normal neurologic examination. Only rarely is specialized study required to rule out angioma, epilepsy, or a mass lesion.

\section{Summary}

Visual symptoms occurred in 41 percent of a selected group of migrainous children diagnosed at The Hospital for Sick Children, Toronto, between 1959 and 1971 . The records of 100 migrainous children experiencing visual phenomena were reviewed. Sixty-seven were reexamined and separate verbal and graphic accounts of their symptoms obtained. The phenomena were classified by type of dominant visuals in to three categories as follows:

1. Binocular visual impairment and scotomas (77 patients). Transient blindness, blurring of vision, and varied scotomas were most common. Vertigo, ataxia, and, less commonly, diplopia and impaired consciousness were associated with visual symptoms.

2. Distortions and hallucinations $116 \mathrm{pa}$ tients). Micropsia and macropsia were the most common phenomena. Inversion, alterations in the perception of motion, and elaborate hallucinations were seen less of ten.

3. Uniocular visual impairment and scotomas ( 7 patients). The visual impairment and scotomas are similar to those of patients in the first category except that the visual field of only one eye is affected. Pain may occur in the ipsilateral eye.

The symptoms of patients in the three categories can be attributed to disturbances maximal in the territory of the basilar (posterior cerebral), middle cerebral, and ophthalmic arteries, respectively.

The visual phenomena varied. Although diverse, they were remarkably constant for a given individual. Visual symptoms in association with paroxysmal headache and nausea, positive heredity, and normal neurologic examination are strong evidence for the diagnosis of migraine, thus reducing the need for more elaborate neurologic study.

\section{Acknowledgments}

The authors thank Dr. J. S. Prichard for permission to examine his patients, who make up a substantial portion of this series; Mrs. Mary Titus and the department of visual education for invaluable help with the graphic material; and Dr. Helen Reid and the department of medical publications for assistance in preparing the manuscript.

\section{KEFERENCES}

1. Mettler CC: History of Medicine. Philadelphia, Blakiston, 1947

2. Critchley M: Migraine: From Cappadocia to Queen Square. In Smith R (Editor): Background to Migraine. London, Heinemann, 1967 , pp 28-38

3. Sacks OW: Migraine: The Evolution of a Common Disorder. Berkeley, University of California Press, 1970

4. Fothergill $\mathrm{J}$ : Remarks on that complaint commonly known under the name of the sick headache. Med Observ Inquiries (London) 6:103-137, 1784

5. Liveing E: On Megrim, Sick-Headache, and Some Allied Disorders. London, Churchill, 1873

6. Airy $H$ : On a distinct form of transient hemiopsia. Phil Trans R Soc Lond [Biol Sci] 160:247-264, 1870

7. Gowers WR: Subjective visual sensations. Trans Ophthalmol Soc UK 15:1-38, 1895

8. Jolly F: Ueber Flimmerskotom und Migrane. Berl Klin Wochenschr 39:973-976, 1902

9. Lashley KS: Patterns of cerebral integration indicated by the scotomas of migraine. Arch Neurol Psychiatry 46:331-339, 1941

10. Richards $W:$ The fortification illusions of migraines. Sci Am 224:88-96, 1971

11. Vahlquist B: Migraine in children. Int Arch Allergy Appl Immunol 7:348-355, 1955

12. Burke EC, Peters GA: Migraine in childhood: A preliminary report. Am $J$ Dis Child $92: 330-336$, 1956

13. Bille B: Migraine in school children: A study of the incidence and short-term prognosis, and a clinical, psychological and encephalographic comparison between children with migraine and matched controls. Acta Paediatr Scand 51(Suppl 136):1-151,1962

14. Marshall CR: Entoptic phenomena associated with the retina. Br J Ophthalmol 19:177-201,1935

15. Nebel BR: The phosphene of quick eye motion. Arch Ophthalmol 58:235-243, 1957

16. Priestly BS, Foree K: Clinical significance of some entoptic phenomena. Arch Ophthalmol 53:390-397, 1955 
17. Harris $\mathrm{W}$ : Hemianopia, with especial reference to its transient varieties. Brain 20:308-364, 1897

18. Wolff HG: Headache and Other Head Pain. Fd 1. London, Oxford University Press, 1948

19. Bickerstaff ER: Basilar artery migraine. Lancet $1: 15-17,1961$

20. O'Brien MD: Cerebral blood changes in migraine. Headache 10:139-143,1971

21. Friedman B: Migraine: With special reference to scintillating scotomata. Eye Ear Nose Throat Mon $50: 52-58,1971$

22. Hanington $E$, Harper AM: The role of tyramine in the aetiology of migraine, and related studies on the cerebral and extracerebral circulations. Headache 8:84-97,1968

23. Bruyn GW, Weenink HR: Migraine accompagnée, a critical evaluation. Headache $6: 1-22,1966$

24. Milner PM: Note on a possible correspondence be- tween the scotomas of migraine and spreading depression of Leäo Electroencephalogr Clin Neurophysiol 10:705, 1958

25. Leão AAP: Pial circulation and spreading depression of activity in cerebral cortex. J Neurophysiol $7: 391-396,1944$

26. Knoll M, Kugler J, Hofer $O$, et al: Effects of chemical stimulation of electrically-induced phosphenes on their band-width, shape, number and intensity. Confin Neurol 23:201-226, 1963

27. Penfield $W$, Jasper $H$ : Epilepsy and the Functional Anatomy of the Human Brain. Boston, Little, Brown and Company, 1954.

28. Penfield W, Perot $P$ : The brain's record of auditory and visual experience: A final summary and discussion. Brain 86:595-696, 1963

29. Hauge $T$ : Catheter vertebral angiography. Acta Radiol (Stockh) 109(Suppl):1-219,1954 


\section{Neurology ${ }^{\circ}$}

Visual symptoms in the migraine syndrome

V. C. Hachinski, J. Porchawka and J. C. Steele

Neurology 1973;23;570

DOI 10.1212/WNL.23.6.570

This information is current as of June 1, 1973

\section{Updated Information \& Services}

Citations

Permissions \& Licensing

Reprints including high resolution figures, can be found at: http://n.neurology.org/content/23/6/570.citation.f ull

This article has been cited by 3 HighWire-hosted articles:

http://n.neurology.org/content/23/6/570.citation.f ull\#\#otherarticles

Information about reproducing this article in parts (figures,tables) or in its entirety can be found online at:

http://www.neurology.org/about/about_the_journ al\#permissions

Information about ordering reprints can be found online:

http://n.neurology.org/subscribers/advertise

Neurology ${ }^{\circledR}$ is the official journal of the American Academy of Neurology. Published continuously since 1951, it is now a weekly with 48 issues per year. Copyright (C) 1973 by the American Academy of Neurology. All rights reserved. Print ISSN: 0028-3878. Online ISSN: 1526-632X.

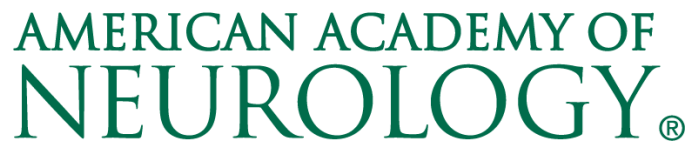

